\title{
Contributions of Foehn and Urban Heat Island to the Extreme High-Temperature Event in Niigata City during the Night of 23-24 August 2018
}

\author{
Akifumi Nishi ${ }^{1}$, Hiroyuki Kusaka ${ }^{2}$, Lidia Lazarova Vitanova ${ }^{2}$, and Yuma Imai ${ }^{1}$ \\ ${ }^{1}$ Graduate School of Life and Environmental Sciences, University of Tsukuba, Tsukuba, Japan \\ ${ }^{2}$ Center for Computational Sciences, University of Tsukuba, Tsukuba, Japan
}

\begin{abstract}
We quantitatively evaluated the contributions of foehn winds and the urban heat island (UHI) effect to an extreme high-temperature nocturnal event at Niigata city on 23-24 August 2018. During this event, southeasterly winds blew continually across the Niigata Plain and temperatures on the plain were higher than those in the windward region of the mountain range. Back-trajectory analysis and numerical simulations with and without topography showed that the southeasterly winds were foehn winds that caused precipitation and latent heating on the windward slope of the mountain range. The foehn winds and UHI contributed about $2.8^{\circ} \mathrm{C}$ and $1.9^{\circ} \mathrm{C}$, respectively, to the extreme high-temperature of $31.0^{\circ} \mathrm{C}$ at $2100 \mathrm{JST}$ in Niigata city. The combined impact of the foehn winds and the UHI at Niigata was about $4.0^{\circ} \mathrm{C}$ during the night. The contribution of the foehn winds was greater at around midnight, whereas that of the UHI was greater during the early night.
\end{abstract}

(Citation: Nishi, A., H. Kusaka, L. L. Vitanova, and Y. Imai, 2019: Contributions of foehn and urban heat island to the extreme high-temperature event in Niigata City during the night of 23-24 August 2018. SOLA, 15, 132-136.)

\section{Introduction}

Nocturnal extreme high-temperature (EHT) events pose widespread public-health risks for senior citizens, such as heatstroke and sleep disturbance (e.g., Semenza et al. 1996) and can severely damage paddy rice growth (e.g., Wassmann et al. 2009). Public concern about the effects of both nocturnal and daytime EHT events has increased greatly in recent years. During a nocturnal EHT event on 23-24 August 2018 on the Niigata Plain, northeastern Japan, temperatures exceeded $40.0^{\circ} \mathrm{C}$ in several areas of Niigata Prefecture and temperatures above $30.0^{\circ} \mathrm{C}$ persisted until 0300 JST (all times hereafter are JST) in Niigata city. Background factors that may have contributed to this nocturnal EHT event include synoptic-scale summer pressure patterns and the presence of typhoon.

At mesoscale, a foehn-type downslope wind may have contributed to this event. Foehn winds can increase temperature by various mechanisms (Takane et al. 2015; Elvidge and Renfrew 2016; Miltenberger et al. 2016; Rotunno and Bryan 2018). In Japan, foehn winds caused the past two record-breaking EHT events on the Kanto Plain, on 16 August 2007 and 23 July 2018 (Takane and Kusaka 2011; Nishi and Kusaka 2019), and other EHT events have also been attributed to foehn winds (e.g., Takane et al. 2015). However, whether a foehn wind or warm advection from a tropical cyclone was the main cause of the nocturnal EHT event recorded at the Niigata Observatory on 23-24 August 2018 remains unclear.

Another possible cause of the 2018 nocturnal EHT event is the urban heat island (UHI) effect. Past studies have confirmed

Corresponding author: Hiroyuki Kusaka, University of Tsukuba, 1-1-1 Tennoudai, Tsukuba, Ibaraki 305-8577, Japan. E-mail: kusaka@ccs.tsukuba. ac.jp.

(C) The Author(s) 2019. This is an open access article published by the Meteorological Society of Japan under a Creative Commons Attribution 4.0 International (CC BY 4.0) license (http://creativecommons.org/license/by/4.0). that even medium-sized cities can produce UHI effects on clear nights (e.g., Figuerola and Mazzeo 1998; Torres-Valcárcel et al. 2015). However, the degree to which the UHI contributed to the nocturnal EHT event at Niigata city has not been quantitatively evaluated.

The purpose of this study was to quantify and compare the effects of foehn winds and the UHI on the nocturnal EHT event of 23-24 August 2018. Most previous studies of foehn winds in Japan have focused on daytime high-temperature events in urban areas rather than on strong wind events in rural areas (e.g., Takane and Kusaka 2011; Takane et al. 2015; Nishi and Kusaka 2019). No previous studies have evaluated and compared the contributions of these two mesoscale phenomena to nocturnal temperature increases. Therefore, the results of this study will contribute not only to understanding the essential mechanism of the recordbreaking EHT event in Niigata city on the night of 23-24 August 2018 but also to better understand the foehn winds on urban climate in Japan.

\section{Data and numerical modeling}

To characterize the nocturnal EHT event on the Niigata Plain, we used surface observational data from the automated meteorological data acquisition system (AMeDAS) and sounding data collected by the Japan Meteorological Agency at Wajima and Tateno observation stations (see Supplements, Fig. S1).

To investigate numerically the event, we ran high-resolution simulations using the Weather Research and Forecasting (WRF) model version 3.9.1 (Skamarock et al. 2008) with a single-layer urban canopy model. The WRF model configuration is explained in Supplement 1 and the urban canopy model configuration in Supplement 2.

To quantitatively estimate the effects of both foehn winds and the UHI on the nocturnal EHT event, we ran a control simulation and three simulations for sensitivity analyses. For the control simulation, we conducted a hindcast of the EHT event with real land-use and topographic data (CTRL simulation). In the first sensitivity analysis, we replaced the urban areas of Niigata city with paddies (NoURB simulation) (see Supplements, Fig. S2). In the second sensitivity analysis, we replaced the real topography with a flat plain, that is, the elevation in the domains of simulation is 0 $\mathrm{m}$ above sea level (NoTOPO simulation). In the third sensitivity analysis, we replaced urban areas with paddies and replaced the real topography with a flat plain (NoURBTOPO simulation).

\section{Results and discussion}

\subsection{Observation data}

At 0600 on 23 August 2018, two tropical cyclones in the Japan region (Fig. 1a) began to generate southeasterly winds that blew from the central Japanese mountains across the Niigata Plain (Fig. 1c). The southeasterly winds gradually strengthened as one of the typhoons approached the Japanese islands. The strongest southeasterly wind $\left(11.0 \mathrm{~m} \mathrm{~s}^{-1}\right)$ was recorded at 0300 on 24 August, when the typhoon reached the Sea of Japan. 
(a)

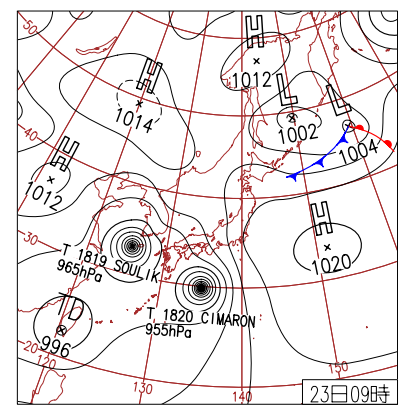

(b)

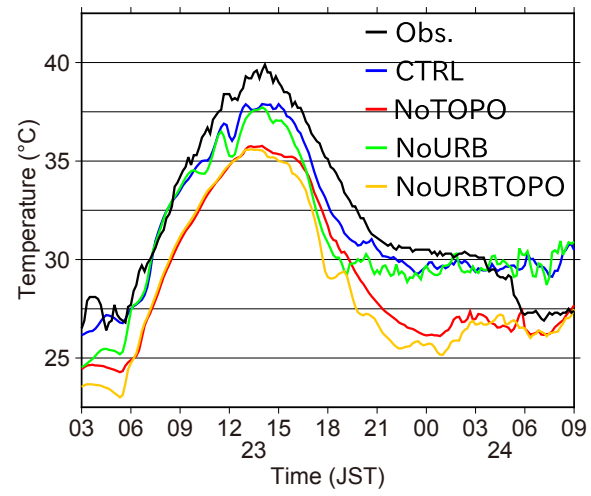

(c)

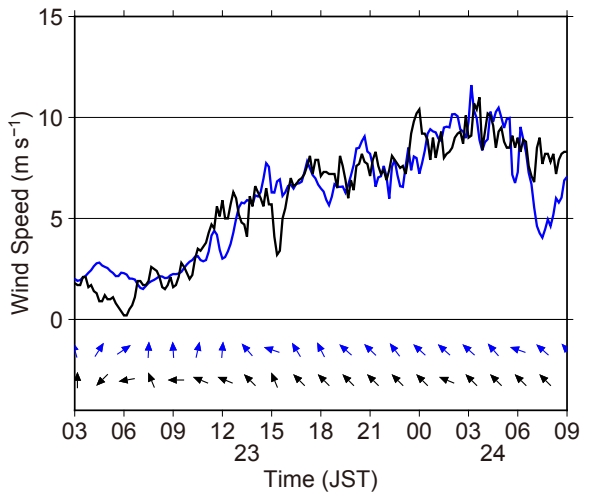

Fig. 1. Meteorological variables during the 23-24 August 2018 EHT event. (a) Weather chart at 0900 on 23 August 2018 (Japan Meteorological Agency 2019b). Time series from 0300 on 23 August to 0900 on 24 August of (b) observed temperature at Niigata observatory (Obs) and temperatures estimated by the WRF model in the control (CTRL), no topography (NoTOPO), no urban area (NoURB), and no urban area and no topography (NoURBTOPO) simulations, and (c) observed (black) and simulated (blue) wind speed and wind direction at Niigata observatory.

At Niigata observatory, the temperature at sunrise (at 0504) was $27.2^{\circ} \mathrm{C}$ (Fig. 1b). It began to rise at 0600 , reaching $39.9^{\circ} \mathrm{C}$ at 1410; this was the highest temperature ever recorded at Niigata (Japan Meteorological Agency 2019a). Relative humidity at 1410 was about $30 \%$ despite it being the moist summer season in Japan (Figure is omitted). The temperature decreased after sunset (at 1740), but it remained above $30.0^{\circ} \mathrm{C}$ until 0300 . These nighttime temperatures are comparable to the average of annual maximum temperature during $1981-2010$ at Niigata $\left(30.6^{\circ} \mathrm{C}\right)$. At around 0400, when precipitation commenced at Niigata observatory, the temperature decreased suddenly (Fig. 1b).

At 2100 on 23 August, southeasterly winds were blowing at $5-10 \mathrm{~m} \mathrm{~s}^{-1}$ across the northern part of the Niigata Plain (around $38^{\circ} \mathrm{N}, 139^{\circ} \mathrm{E}$, Fig. 2a) and the surface air temperature was above $31.0^{\circ} \mathrm{C}$ (Fig. 2b). On the windward side of the mountains (e.g., around the northern Kanto plain shown in Fig. S1b of Supplements), winds were weaker $\left(\leq 1.0 \mathrm{~m} \mathrm{~s}^{-1}\right)$ and temperatures were below $28.0^{\circ} \mathrm{C}$. Thus, at 2100 on 23 August the temperature at Niigata was about $3^{\circ} \mathrm{C}$ higher than it was on the windward side of the mountains. While the southeasterly winds were blowing across the Niigata Plain, precipitation was occurring on the windward slope of the mountains (Figure is omitted). These conditions of wind, temperature, and precipitation are characteristic of foehn events.

Here, we focus on nocturnal temperatures in the urban area of Niigata city, where the nighttime temperature (over $30.0^{\circ} \mathrm{C}$ ) was higher than in the surrounding rural area $\left(27.0-30.0^{\circ} \mathrm{C}\right)$. This temperature distribution suggests that the UHI effect was also active during the nocturnal EHT event of 23-24 August 2018.

\subsection{Results of the control simulation}

Comparison of CTRL simulation results with observation data showed that the WRF reproduced well the temporal changes of temperature and wind at Niigata city (Figs. 1b and 1c), although the simulation slightly underestimated daytime temperatures. The simulation could not capture the observed sudden temperature drop around 0400 on 23 August because the WRF model failed to reproduce precipitation in Niigata around 0400 on 23 August. The WRF model also reproduced well the spatial distributions of surface wind and temperature on the Niigata Plain (Fig. 2c).

Simulated potential temperature along cross-section A-B at 2100 on 23 August (Fig. 3) shows that potential temperature contours between 304 and $310 \mathrm{~K}$ rapidly descended the leeward slope of the mountain range (from $139.3^{\circ} \mathrm{N}$ to $139.2^{\circ} \mathrm{N}$, Fig. 3), as did wind speeds exceeding $15 \mathrm{~m} \mathrm{~s}^{-1}$. These phenomena together indicate the development of downslope winds. The simulated distribution of 12-h accumulated precipitation up to 2100 on 23 August (Fig. 4) suggests that the downslope winds are the foehn winds.

\subsection{Back-trajectory analysis}

Back-trajectory analysis can be used to determine whether or not downslope winds are foehn winds (e.g., Takane and Kusaka 2011; Takane et al. 2015; Miltenberger et al. 2016; Elvidge and Renfrew 2016; Ishizaki and Takayabu 2009). We conducted back-trajectory analysis around the Niigata city area by releasing 121 air parcels at 2100 on 23 August 2018 from the surface level of the model grid within an area of $484 \mathrm{~km}^{2}$ around Niigata AMeDAS observatory. Those air parcels were then tracked backward every $3 \mathrm{~min}$ from the time of their release to 0900 on 23 August by using wind components of the CTRL simulation.

The back-trajectory analysis results indicated that the air parcels at the surface near Niigata city at 2100 on 23 August 2018 crossed around the Nasu mountain (see Supplements, Fig. S1b) from the northern Kanto Plain (Fig. 5a). Most of the air parcels (92\%) were at heights of about $1.0 \mathrm{~km}$ above sea level (ASL) or lower when they were over the northern Kanto Plain (Fig. 5b). The average height of the air parcels passing over the most windward mountain crest was about $1.2 \mathrm{~km}$ ASL. These results suggest that the southeasterly winds observed at Niigata city during the nocturnal EHT event were "thermodynamic foehn (wet foehn)" winds, which characteristically ascend the windward slopes of mountain ranges accompanied by precipitation and latent heat release and then descend the leeward slopes accompanied by adiabatic heating (e.g. Seibert 1990; Miltenberger et al 2016; Elvidge and Renfrew 2016).

We estimate the contribution of foehn winds to temperature change along each trajectory $\left(\Delta T_{F o h n}\right)$, referring Elvidge and Renfrew (2016) as follows:

$$
\begin{aligned}
& \Delta T_{\text {Foehn }}=\Delta T_{\text {total }}-\Delta T_{U H I} . \\
& \Delta T_{\text {total }}=\Delta T_{A d}+\Delta T_{P r}+\Delta T_{\text {Other }}, \\
& \Delta T_{A d}=\Gamma_{d}\left(Z_{b}-Z_{a}\right), \\
& \Delta T_{P r}=\left(\theta_{a}-\theta e_{a}\right)-\left(\theta_{b}-\theta e_{b}\right), \\
& \Delta T_{\text {Other }}=\left(\theta e_{a}-\theta e_{b}\right),
\end{aligned}
$$

Here, $T, Z, \theta$, and $\theta e$ indicate the air temperature, altitude, potential temperature, and equivalent potential temperature of the air parcels, respectively. The variables with subscript " $a$ " mean the values at the released position of the air parcels of backward trajectory around the Niigata city area (at 2100 on 23 August). On the other hand, the variables with subscript " $b$ " mean the values at the position of each air parcel when each air parcel was located at the latitude of $36.0^{\circ} \mathrm{N}$ (around 1400 on 23 August). $\Gamma_{d}$ is dry lapse rate (assumed to be $-1.0 \times 10^{-2}{ }^{\circ} \mathrm{C} \mathrm{m}^{-1}$ here).

$\Delta T_{A d}$ and $\Delta T_{P r}$ indicate the adiabatic effect due to the descent of the air parcels and the diabatic effect due to the phase change of water, respectively. $\Delta T_{\text {Other }}$ means the diabatic effect excluding $\Delta T_{P r}$ (e.g. the radiation, land surface, and PBL processes). These 
(a)

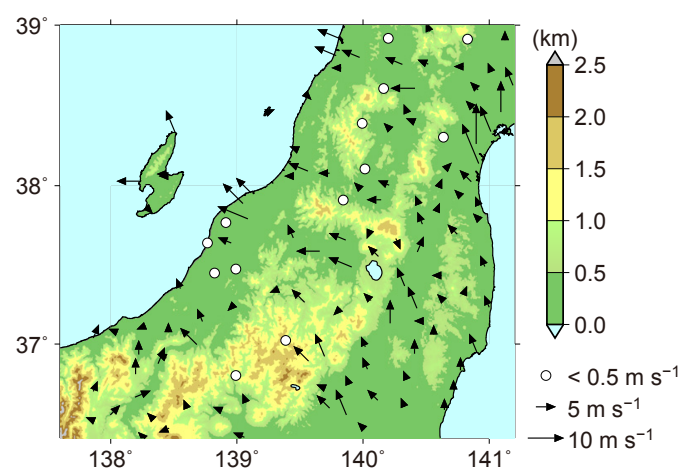

(c)

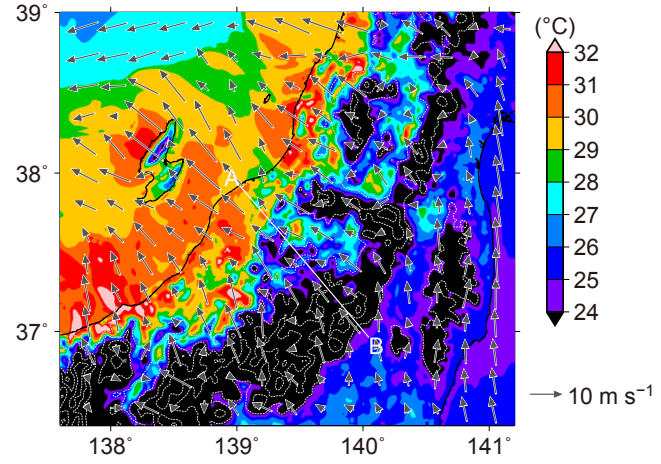

(b)

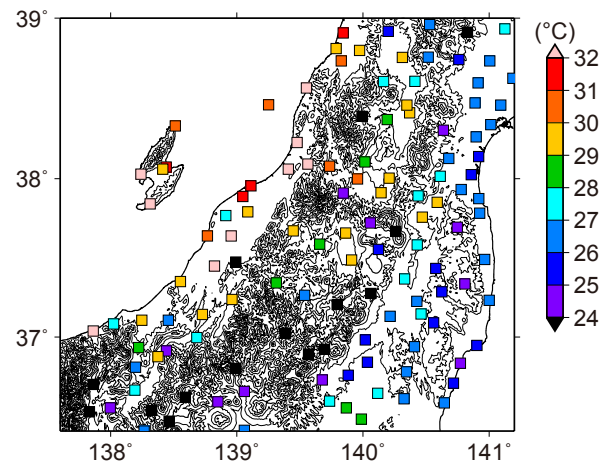

Fig. 2. Surface distributions at 2100 on 23 August 2018 of observed (a) surface wind and (b) surface air temperature. Color shadings in (a) indicate the elevation. Contours in (b) show the elevation (elevation ASL); thin contours are at $0.25 \mathrm{~km}$ intervals, and bold contours are at $1.0 \mathrm{~km}$ intervals. (c) Distributions of surface wind (vectors) and surface air temperature (color scale) simulated by the WRF model. Contours (contour interval, $0.5 \mathrm{~km}$ ) show the topography. A-B is the location of the crosssection in Fig. 3.

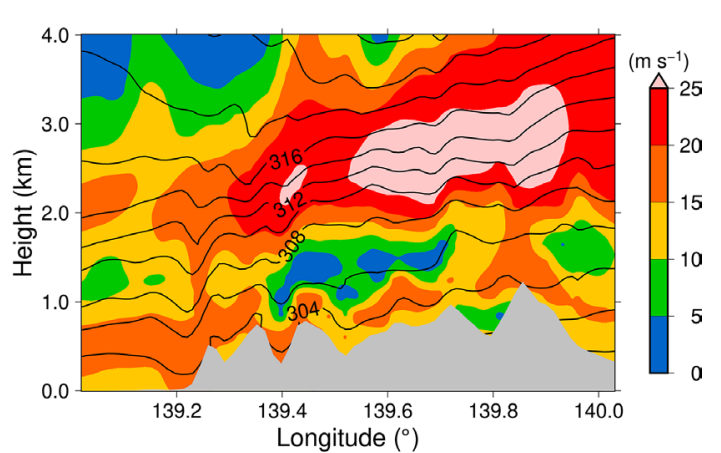

Fig. 3. Simulated potential temperature (contours) and wind speed (color scale) along cross-section A-B (location in Fig. 2c) at 2100 on 23 August 2018. The light gray area is the terrain.

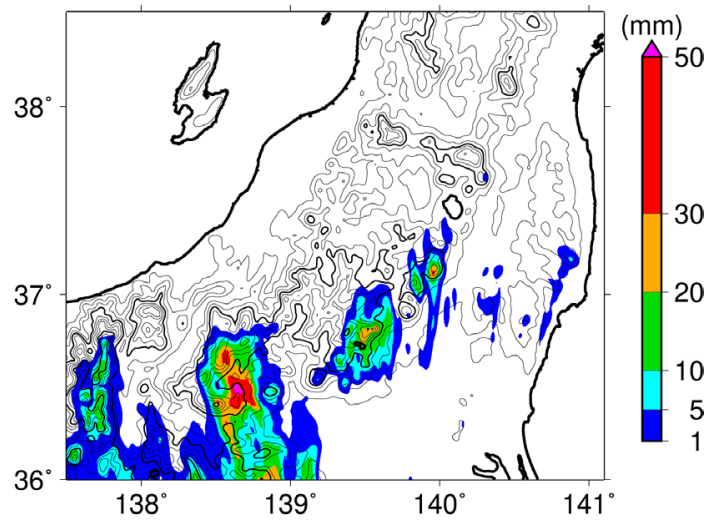

Fig. 4. Simulated surface distribution of 12 -h accumulated precipitation up to 2100 on 23 August 2018. Contours show topography (elevation ASL); thin contours are at $0.25 \mathrm{~km}$ intervals, and bold contours are at $1.0 \mathrm{~km}$ intervals. (a)

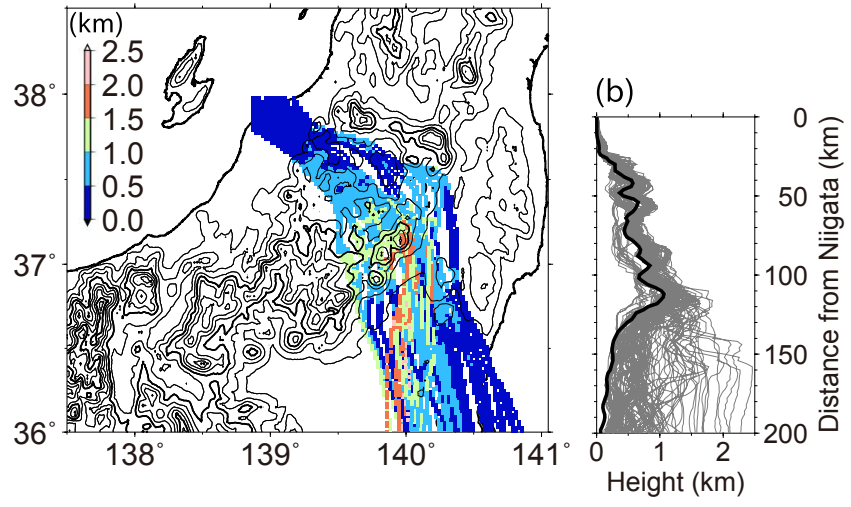

Fig. 5. Back-trajectories of 121 air parcels from the vicinity of Niigata city from 2100 to 0900 on 23 August. (a) Map view of parcel positions. Colors indicate parcel height ASL. Contours show topography (elevation ASL); thin contours are at $0.25 \mathrm{~km}$ intervals, and bold contours are at $1.0 \mathrm{~km}$ intervals. (b) Height (ASL)-distance diagram of parcel trajectories (gray lines). The bold black line indicates terrain elevation along the ensembleaveraged trajectory of the 121 air parcels.

values are calculated along each trajectory. $\Delta T_{U H I}$ is the effect of UHI which is estimated in the next section. As a result, the averaged value of $\Delta T_{\text {total }}$ is $4.8^{\circ} \mathrm{C}$. The averaged value of $\Delta T_{F o e h n}$ can be calculated if $\Delta T_{U H I}$ is estimated.

\subsection{Sensitivity analyses}

Comparison of the CTRL (Fig. 2c) and NoURB (Fig. 6a) simulation results for the Niigata city area at 2100 on 23 August 2018 showed that temperatures estimated by the CTRL simulation were $1.0-2.0^{\circ} \mathrm{C}$ higher than those estimated by the NoURB simulation (Fig. 6b). That is, the simulated UHI effect in Niigata city was $1.0-2.0^{\circ} \mathrm{C}$, which is consistent with the observed temperature difference between the central Niigata city area (the Niigata obser- 
(a)

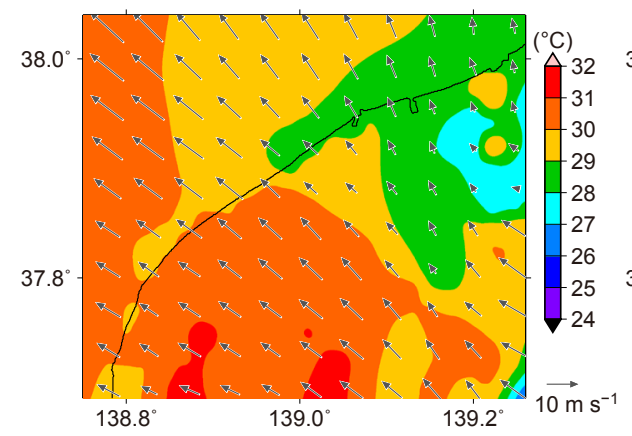

(b)

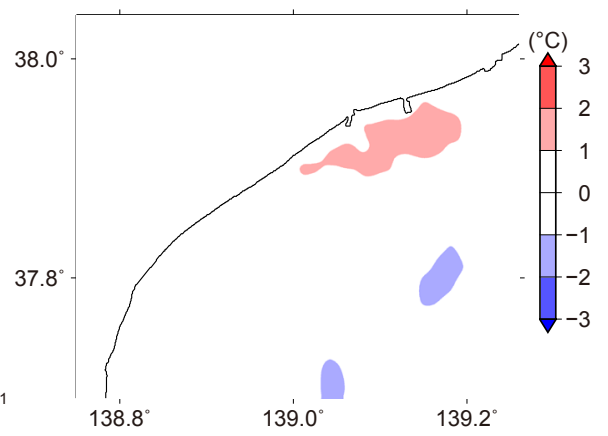

Fig. 6. Results of the NoURB simulation. (a) Simulated distributions at 2100 on 23 August 2018 of surface wind (vectors) and surface air temperature (color scale). (b) Temperature differences between CTRL and NoURB simulation.

(a)

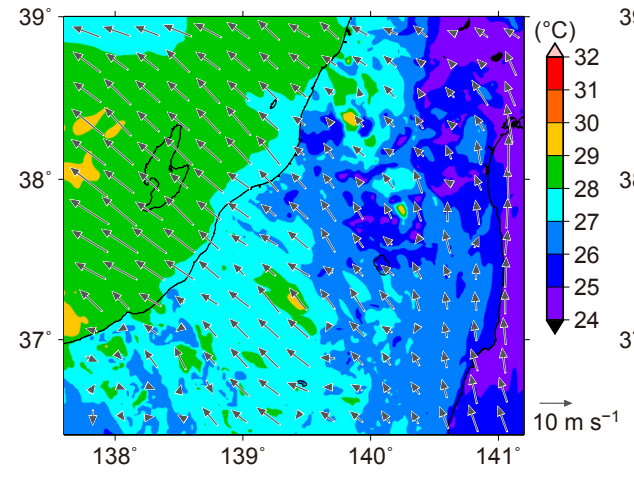

(b)

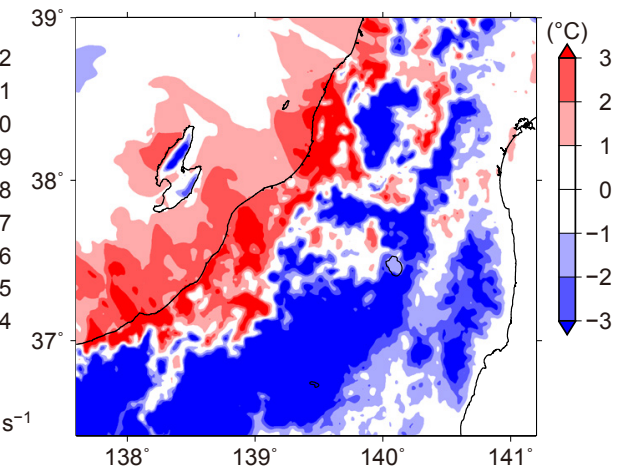

Fig. 7. Results of the NoTOPO simulation. (a) Simulated distributions at 2100 on 23 August 2018 of surface wind (vectors) and surface air temperature (color scale). (b) Temperature differences between CTRL and NoTOPO simulation.

vatory) and the rural area nearby the Niigata city.

Comparison of the CTRL (Fig. 2c) and NoTOPO (Fig. 7a) simulation results showed that the temperatures estimated at 2100 on 23 August across the entire Niigata Plain by the CTRL simulation were higher than those estimated by the NoTOPO simulation (Fig. 7b). Moreover, our analysis results indicate that both the foehn winds and the UHI effect contributed to the nocturnal EHT event on 23-24 August 2018.

We quantitively examine the contributions of UHI and foehn winds to the surface air temperature at Niigata. The model error of surface air temperature in the CTRL simulation was about $2.0^{\circ} \mathrm{C}$. However, it can be assumed that the model error is not so different among control and sensitivity simulations in general. Therefore, it can be allowed to discuss the anomaly between the simulations.

At 2100 on 23 August (at the time when the parcels released), the contribution of UHI to the surface air temperature (CTRL NoURB; Fig. 1b) was $1.9^{\circ} \mathrm{C}\left(=\Delta T_{U H I}\right)$. On the other hand, the contribution of foehn winds (CTRL - NoTOPO; Fig. 1b) was $2.8^{\circ} \mathrm{C}$ (equivalent to $\Delta T_{F o h e n}$ ). Consequently, the total contribution of UHI and foehn winds was $4.7^{\circ} \mathrm{C}$. This result was consistent with the total temperature change calculated from Eq. (1) in Section 3.3.

\subsection{Relative influences of foehn winds and UHI on surface air temperature}

We now focus on the relative influences of the foehn winds and UHI on temporal variations of temperature during the nocturnal EHT event (Fig. 1b).

At 1800 on 23 August, the contribution of the foehn winds to surface air temperature (CTRL - NoTOPO; Fig. 1b) was about $1.0^{\circ} \mathrm{C}$ and that of the UHI (CTRL - NoURB; Fig. 1b) was about $2.8^{\circ} \mathrm{C}$. Generally, the UHI effect is greatest for the several hours following sunset (e.g., Oke 1982), which is consistent with our simulated result showing a large influence of the UHI at 1800 . At 2100 on 23 August, the contributions of the foehn winds and UHI to the surface air temperature at Niigata were $2.8^{\circ} \mathrm{C}$ and $1.9^{\circ} \mathrm{C}$, respectively. At both 0000 and 0300 on 24 August, they were about $3.2^{\circ} \mathrm{C}$ and $0.8^{\circ} \mathrm{C}$, respectively. During the period from 1800 on 23 August to 0300 on 24 August, wind speed gradually increased to more than $10.0 \mathrm{~m} \mathrm{~s}^{-1}$. Because the difference of the degree of radiative cooling between urban and rural areas has an important influence on the nocturnal UHI effect, a UHI cannot form or be maintained when winds are strong; the decrease of the UHI effect on the simulated temperature is therefore consistent with the increased wind speed around 0300 on 24 August. Otherwise, if the winds remained weak, the UHI effect is weakened gradually with time during the night.

The results of our simulations indicate that the UHI made a greater contribution to the 2018 nocturnal EHT event early in the night, but the contribution of foehn winds increased toward midnight. The simulated combined contributions of the foehn winds and the UHI at Niigata (CTRL - NoURBTOPO) at 1800 and 2100 on 23 August and at 0000 on 24 August were $4.0,4.1$, and $4.0^{\circ} \mathrm{C}$, respectively (Fig. 1b).

\section{Conclusions}

We conducted numerical simulations to quantitatively examine the contributions of foehn winds and urban heat island effects to the extreme high-temperature event at Niigata during the night of 23 August and early morning of 24 August 2018. Our main results are as follows:

- On 23 August 2018, two tropical cyclones were approaching the Japanese islands. Both observation data and numerical simulations indicated that nocturnal temperatures remained above 
$30.0^{\circ} \mathrm{C}$ until 0300 on 24 August. Southeasterly winds blew continuously during this nocturnal EHT event.

- Observation data showed that nocturnal temperatures were higher on the Niigata Plain than on the windward side of the mountain range. Back-trajectory analysis and numerical simulations with and without topography (CTRL and NoTOPO) showed the southeasterly winds to be foehn winds that blew over the Niigata Plain throughout the nocturnal EHT event. While the foehn winds blew, there was rain on the windward side of the mountain range. These results suggest that the foehn phenomenon on the day of the nocturnal EHT event was the result of latent heating and precipitation. The contribution of the foehn winds to the EHT in Niigata city was about $2.8^{\circ} \mathrm{C}$ at 2100.

- Observation data indicated that a UHI effect occurred in Niigata city at 2100 JST. Numerical simulations, both CTRL and NoURB, showed that the UHI increased surface air temperatures in Niigata city by about $1.9^{\circ} \mathrm{C}$ at $2100 \mathrm{JST}$.

- The combined effect of the foehn winds and the UHI at Niigata was about $4.0^{\circ} \mathrm{C}$ during the night of $23-24$ August 2018 . The contribution of the foehn winds was greater around midnight, whereas the contribution of the UHI was greater early in the night.

\section{Acknowledgments}

This work was supported by the "Interdisciplinary Computational Science Program" at the Center for Computational Sciences, University of Tsukuba. This research was partly supported by the Environment Research and Technology Development Fund (2-1905) of the Environmental Restoration and Conservation Agency of Japan. We used the Generic Mapping Tool (GMT) and NCAR Command Language (NCL) to draw the figures in the present study.

Edited by: T. Watanabe

\section{Supplements}

Supplement 1 describes the configuration of the numerical simulation.

Supplement 2 describes the configuration of the urban canopy model.

\section{References}

Chen, F., and J. Dudhia, 2001: Coupling an advanced land-surface/ hydrology model with the Penn State/NCAR MM5 modeling system. Part I: Model description and implementation. Mon. Wea. Rev., 129, 569-585.

Dudhia, J., 1989: Numerical study of convection observed during the Winter Monsoon Experiment using a mesoscale two-dimensional model. J. Atmos. Sci., 46, 3077-3107.

Elvidge, A. D., and I. A. Renfrew, 2016: The causes of foehn warming in the lee of mountains. Bull. Amer. Meteor. Soc., 97, 455-466, doi:10.1175/BAMS-D-14-00194.1.

Figuerola, P. I., and N. A. Mazzeo, 1998: Urban-rural temperature differences in Buenos Aires. Int. J. Climatol., 18, 1709-1723.

Hann, J., 1866: Zur frage über den ursprung des Föhn. Z. Österr. Ges. Meteor., 1, 257-263.

Hann, J., 1867: Der Föhn in den österreichischen Alpen. Z. Österr. Ges. Meteor., 2, 433-445.

Hong, S. Y., J. Dudhia, and S. H. Chen, 2004: A revised approach to ice microphysical processes for the bulk parameterization of clouds and precipitation. Mon. Wea. Rev., 132, 103-120.

Hong, S. Y., Y. Noh, and J. Dudhia, 2006: A new vertical diffusion package with an explicit treatment of entrainment processes. Mon. Wea. Rev., 134, 2318-2341, doi:10.1175/MWR3199.1.
Ishizaki, N., and I. Takayabu, 2009: On the warming events over Toyama Plain by using NHRCM. SOLA, 5, 129-132, doi: 10.2151/sola.2009-033.

Japan Meteorological Agency, 2019a: Recorded values from 1st to 10th in observation history at Niigata (in Japanese) (Available online at http://www.data.jma.go.jp/obd/stats/etrn/view/rank s. php?prec $\_$no $=54 \&$ block $\_$no $=47604 \&$ year $=\&$ month $=13 \&$ day $=$ \&view $=\mathrm{h} \overline{0}$, accessed 8 March 2019).

Japan Meteorological Agency, 2019b: Daily weather chart in August 2018 (in Japanese) (Available online at https://www.data.jma. go.jp/fcd/yoho/data/hibiten/2018/201808.pdf, accessed 8 March 2019).

Kain, J. S., 2004: The Kain-Fritsch convective parameterization: An update. J. Appl. Meteor., 43, 170-181.

Miltenberger, A. K., S. Reynolds, and M. Sprenger, 2016: Revisiting the latent heating contribution to foehn warming: Lagrangian analysis of two foehn events over the Swiss Alps. Quart. J. Roy. Meteor. Soc., 142, 2194-2204, doi:10.1002/qj.2816.

Mlawer, E. J., S. J. Taubman, P. D. Brown, M. J. Iacono, and S. A. Clough, 1997: Radiative transfer for inhomogeneous atmospheres: RRTM, a validated correlated- $\mathrm{k}$ model for the longwave. J. Geophys. Res., 102, 16663-16682.

Nishi, A., and H. Kusaka, 2019: Effect of foehn wind on recordbreaking high temperature event $\left(41.1^{\circ} \mathrm{C}\right)$ at Kumagaya on 23 July 2018. SOLA, 15, 17-21, doi:10.2151/sola.2019-004.

Oke, T. R., 1982: The energetic basis of the urban heat island. Quart. J. Roy. Meteor. Soc., 108, 1-24.

Richner, H., and P. Hächler, 2013: Understanding and forecasting Alpine foehn. Mountain Weather Research and Forecasting: Recent Progress and Current Challenges. F. K. Chow, S. F. J. De Wekker, and B. J. Snyder, Eds., Springer, Germany, 219260.

Rotunno, R., and G. Bryan, 2018: Numerical simulations of two-layer flow past topography. Part I: The leeside hydraulic jump. $J$. Atmos. Sci., 75, 1231-1241, doi:10.1175/JAS-D-17-0306.1.

Sailor, D. J., and L. Lu, 2004: A top-down methodology for developing diurnal and seasonal anthropogenic heating profiles for urban areas. Atmos. Environ., 38, 2737-2748.

Seibert, P., 1990: South föhn studies since the ALPEX experiment. Meteor. Atmos. Phys., 43, 91-103.

Semenza, J. C., C. H. Rubin, K. H. Falter, J. D. Selanikio, W. D. Flanders, H. L. Howe, and J. L. Wilhelm, 1996: Heat-related deaths during the July 1995 Heat Wave in Chicago. N. Engl. J. Med., 335, 84-90, doi:10.1056/NEJM199607113350203.

Skamarock, W. C., J. B. Klemp, J. Dudhia, D. O. Gill, D. M. Barker, M. G. Duda, X. Huang, W. Wang, and J. G. Powers, 2008: A description of the Advanced Research WRF Version 3. NCAR Tech. Note NCAR/TN-4751STR, 126 pp. (Available online at http://www2.mmm.ucar.edu/wrf/users/docs/arw_v3.pdf, accessed 8 March 2019).

Takane, Y., and H. Kusaka, 2011: Formation mechanisms of the extreme high surface air temperature of $40.9^{\circ} \mathrm{C}$ observed in the Tokyo metropolitan area: Considerations of dynamic foehn and foehnlike wind. J. Appl. Meteor. Climatol., 50, 1827-1841, doi:10.1175/JAMC-D-10-05032.1.

Takane, Y., H. Kusaka, and H. Kondo, 2015: Investigation of a recent extreme high-temperature event in the Tokyo metropolitan area using numerical simulations: the potential role of a 'hybrid' foehn wind. Quart. J. Roy. Meteor. Soc., 141, 1857-1869, doi: 10.1002/qj.2490.

Torres-Valcárcel, Á. R., J. Harbor, A. L. Torres-Valcárcel, and C. J. González-Avilés, 2015: Historical differences in temperature between urban and non-urban areas in Puerto Rico. Int. J. Climatol., 35, 1648-1661, doi:10.1002/joc.4083.

Wassmann, R., S. V. K. Jagadish, S. Heuer, A. Ismail, E. Redona, R. Serraj, R. K. Singh, G. Howell, H. Pathak, and K. Sumfleth, 2009: Climate change affecting rice production: the physiological and agronomic basis for possible adaptation strategies. $A d v$. Agron., 101, 59-122.

Whiteman, C. D., 2000: Mountain Meteorology: Fundamentals and Applications. Oxford University Press, USA, $355 \mathrm{pp}$.

Manuscript received 8 March 2019, accepted 26 April 2019

SOLA: https://www.jstage.jst.go.jp/browse/sola/ 